\title{
Frequency of IFNY-producing T cells correlates with seroreactivity and activated T cells during canine Trypanosoma cruzi infection
}

\author{
Ashley N Hartley ${ }^{1,2}$, Gretchen Cooley ${ }^{1}$, Sarah Gwyn ${ }^{1}$, Marcela M Orozco ${ }^{3}$ and Rick L Tarleton ${ }^{1,4^{*}}$
}

\begin{abstract}
Vaccines to prevent Trypanosoma cruzi infection in humans or animals are not available, and in many settings, dogs are an important source of domestic infection for the insect vector. Identification of infected canines is crucial for evaluating peridomestic transmission dynamics and parasite control strategies. As immune control of T. cruzi infection is dependent on humoral and cell-mediated immune responses, we aimed to define a serodiagnostic assay and T cell phenotypic markers for identifying infected dogs and studying the canine T. cruzi-specific immune response. Plasma samples and peripheral blood mononuclear cells (PBMCs) were obtained from forty-two dogs living in a T. cruzi-endemic region. Twenty dogs were known to be seropositive and nine seronegative by conventional serologic tests two years prior to our study. To determine canine seroreactivity, we tested sera or plasma samples in a multiplex bead array against eleven recombinant T. cruzi proteins. Ninety-four percent (17/18) of dogs positive by multiplex serology were initially positive by conventional serology. The frequency of IFNy-producing cells in PBMCs responding to T. cruzi correlated to serological status, identifying 95\% of multiplex seropositive dogs. Intracellular staining identified $\mathrm{CD}^{+}$and $\mathrm{CD} 8^{+} \mathrm{T}$ cell populations as the sources of $\mathrm{T}$. cruzi lysate-induced IFNy. Low expression of CCR7 and CD62L on CD4 ${ }^{+}$and $C D 8^{+} T$ cells suggested a predominance of effector/effector memory $T$ cells in seropositive canines. These results are the first, to our knowledge, to correlate T. cruzi-specific antibody responses with T cell responses in naturally infected dogs and validate these methods for identifying dogs exposed to T. cruzi.
\end{abstract}

\section{Introduction}

Trypanosoma cruzi infects humans, wildlife, and domestic animals throughout the Americas. Worldwide, it is estimated that at least ten million individuals are chronically infected with $T$. cruzi, with twenty-five million more are at risk of infection [1]. T. cruzi infection predominantly burdens countries of Central and South America but encompasses all of the Americas including the United States, contributing 14000 deaths annually and 700000 daily adjusted life years [2]. Current methods of parasite control, diagnostics, and treatment are inadequate in completely disrupting transmission as new infections occur annually, and no vaccines are currently available for human or veterinary use.

\footnotetext{
* Correspondence: tarleton@uga.edu

${ }^{1}$ Center for Tropical and Emerging Global Diseases, University of Georgia, Athens, GA 30602, USA

${ }^{4}$ Department of Cellular Biology, University of Georgia, Athens, GA 30602, USA Full list of author information is available at the end of the article
}

Dogs play a significant role in T. cruzi epidemiology and ecology as reservoirs for infection [3]. Preferential [4] and host tolerant [5] vectorial feeding of dogs, higher T. cruzi infectivity of Triatoma infestans upon feeding on dogs compared to human feeding [6], and the close proximity of dogs to humans in domiciles in T. cruzi endemic regions [7] identifies dogs as a critical control point for T. cruzi transmission. Strategies for interrupting transmission by targeting the dog have included insecticideimpregnated dog collars [8] and various means of vaccination [9-11]. Despite these efforts, peridomestic T. cruzi transmission still occurs between humans, dogs, and the insect vector [3]. Identifying infected canines and understanding the immune mechanisms responsible for canine T. cruzi recognition and control are critical for designing and evaluating future intervention strategies targeting canines.

\section{Biomed Central}

(c) 2014 Hartley et al.; licensee BioMed Central Ltd. This is an open access article distributed under the terms of the Creative Commons Attribution License (http://creativecommons.org/licenses/by/2.0), which permits unrestricted use, distribution, and reproduction in any medium, provided the original work is properly cited. 
Because the results of individual serological tests for T. cruzi infection are not considered to be definitive, positive responses on a minimum of two tests is generally recommended to identify infected humans [12-14], and dogs $[15,16]$. For identifying circulating anti-T. cruzi antibodies, hemagglutination, complement fixation, indirect immunofluorescence, and direct agglutination tests have been standardized for canine sera [17]. These methods, also known broadly as conventional serological assays, predominantly utilize insect stage epimastigote-derived antigens for seroreactivity testing. In an attempt to improve the quality of serological tests for detection of $T$. cruzi infection, we developed a multiplex bead array format utilizing recombinant $T$. cruzi proteins selected for their predicted expression during mammalian infection stages [18], high abundance in trypomastigote and amastigote proteomes [19], and ability to detect the broad array of responses observed in T. cruzi-infected humans [20]. Investigating serological assays employing mammalianstage derived proteins could maximize discrimination of seropositive and seronegative canines, thereby reducing the need for multiple tests to identify seroreactive dogs during intervention campaigns.

Studies of human T. cruzi infection and experimental animal models have highlighted the role antibodies [21-23], CD4 ${ }^{+}$and $\mathrm{CD}^{+} \mathrm{T}$ cells [24-26], and effector cytokines $[27,28]$ serve in immune control of $T$. cruzi, predicting disease development, and determining treatment success. Identification of T. cruzi-specific $\mathrm{CD}^{+} \mathrm{T}$ cells by class I MHC tetramers for mice [29] and humans [27] has facilitated monitoring of cell surface marker expression and effector function of $T$. cruzi-specific $\mathrm{T}$ cells. In particular, correlation of parasitological cure with increased CD127 and CD62L expression by T. cruzispecific $\mathrm{CD}^{+} \mathrm{T}$ cells in benznidazole-treated mice has identified biomarkers for evaluating parasite burden in vivo [30]. Characterizing similar canine T cell phenotypes and effector cytokine production is critical for understanding the development of an appropriate $T$. cruzi-specific immune response in the dog and evaluating modulation of this response following intervention strategies targeting the dog.

The aim of this study was to test the use of a multiplex serodiagnostic assay for $T$. cruzi in dog sera or plasma and to further evaluate $\mathrm{T}$ cell phenotypes and effector cytokine production associated with canine T. cruzi infection. Peripheral blood was collected from dogs previously tested by conventional serology and/or xenodiagnosis and living in a T. cruzi-endemic region of northern Argentina. Plasma were submitted to multiplex bead array analysis using eleven recombinant $T$. cruzi proteins, previously described for identifying seroreactive humans and evaluating treatment success [20], and PBMCs were assessed for IFN $\gamma$ production in response to $T$. cruzi amastigote antigens by ELISpot. Utilizing recently identified $\mathrm{T}$ cell reagents identified for the dog (Hartley and Tarleton, unpublished), we assessed expression of canine $\mathrm{T}$ cell surface markers associated with naïve or central memory and activated T cells. The results of this study determined dogs living in $T$. cruzi-endemic regions develop robust anti-T. cruzi antibody responses which correlate with $\mathrm{T}$ cell effector and activation phenotypes. The serological and $\mathrm{T}$ cells assays described here provide a platform for monitoring canine immune responses and for developing and evaluating canine-centric T. cruzi intervention strategies.

\section{Materials and methods \\ Animals}

A maximum of $10 \mathrm{~mL}$ of blood from 42 dogs living in four villages in Pampa del Indio, Chaco, Argentina were drawn into heparinized tubes (BD Vacutainer, BD, Franklin Lakes, NJ, USA) by venipuncture. A proportion of these dogs had been previously screened and found to be seropositive or seronegative for $T$. cruzi by conventional serology (see below). Approximately $50 \mathrm{~mL}$ of blood from three clinically healthy dogs and sera from 5 additional healthy dogs from the United States were obtained to serve as controls. Isolation of peripheral blood mononuclear cells (PBMCs) occurred within $24 \mathrm{~h}$ of collection. Briefly, PBMCs were isolated by density gradient centrifugation on Lymphocyte Separation Medium (MP Biomedicals, Solon, OH, USA), resuspended in complete RPMI 1640 supplemented with 10\% heat-inactivated FCS (HyClone Laboratories, ThermoScientific, Logan, UT, USA), and stored frozen at $-80{ }^{\circ} \mathrm{C}$. These purification, storage, and recovery procedures yielded $>80 \%$ viability for Argentinean and $>95 \%$ viability for North American dogs as determined by microscopic examination of trypan blue exclusion. Plasma samples were collected during PBMC isolation and stored frozen at $-20{ }^{\circ} \mathrm{C}$. Informed oral consent was requested and obtained from each head of household for samples collected in Argentina. Animal use protocols for samples collected in the United States were approved by the University of Georgia Institutional Animal Care and Use Committee. Blood collection in Argentina was conducted according to the protocol approved by the Argentinean "Dr Carlos Barclay" Independent Ethical Committee for Clinical Research (IRB No. 00001678, NIH registered, and Protocol No. TW-01-004).

\section{Initial conventional serology and xenodiagnosis}

Indirect hemagluttination assay (IHA) and an in-house enzyme-linked immunosorbent assay (ELISA) modified from a standardized protocol [15] were used to test sera for anti-T. cruzi antibodies two years prior to collection of PBMC and plasma for this study [31]. Sera were considered discordant if results of IHA and ELISA reactivity 
mismatched. A subset of animals were also examined by xenodiagnosis, as previously outlined [31] and notated in Table 1. Briefly, boxes containing uninfected fourth-instar nymphs of $T$. infestans were exposed to the abdomen of an individual dog. Insect feces were examined microscopically at 30 and 60 days later for T. cruzi infection.

\section{T. cruzi amastigote lysate}

Brazil strain trypomastigotes were cultured overnight in pH 5 RPMI 1640 supplemented with 10\% FCS and $10 \mathrm{mM}$ phosphate citrate buffer to transform trypomastigotes into amastigotes. After two PBS washes, parasites were frozen at $-20{ }^{\circ} \mathrm{C}$. Frozen aliquots were subjected to five freeze/thaw cycles followed by three 10s sonications in a FS15 sonicator (Fisher Scientific, Pittsburgh, PA, USA). The supernatant of a $12000 \mathrm{rpm}$ centrifugation was collected, filter sterilized, and protein concentration determined by Bradford assay.

\section{Serology testing with protein multiplex bioassay}

Canine plasma samples were tested with a recombinant T. cruzi protein multiplex assay previously described in detail for testing $T$. cruzi reactivity of human sera samples [20]. Briefly, sera or plasma are diluted 1:500 and incubated with a pool of 11 recombinant proteins attached to addressable Liquichip Ni-NTA beads (Qiagen Inc, Valencia, CA, USA) and T. cruzi amastigote lysate coupled to Carboxy-Ni-NTA beads (Qiagen Inc). Following washing, antibody binding was detected with goat anti-dog IgG conjugated to phycoerythrin (Santa Cruz Biotechnology Inc, Santa Cruz, CA, USA) and quantified on a Bio-Plex Suspension Array System (Bio-Rad, Hercules, CA, USA). Serum samples were assayed in duplicate and weighted mean fluorescence intensity (MFI) was calculated. The ratio of the specific MFI for each antigen versus a negative control (green fluorescent protein) protein was calculated for each antigen and sera or plasma in the assay.

\section{IFNץ ELISpot assays}

Four hundred thousand PBMCs were cultured in media, $2 \mathrm{ng} / \mathrm{mL}$ phorbol 12-myristate 13-acetate (PMA) and $500 \mathrm{ng} / \mathrm{mL} \mathrm{Ca}{ }^{2+}$ ionomycin (both Sigma-Aldrich, St. Louis, MO, USA), or $10 \mu \mathrm{g} / \mathrm{mL}$ T. cruzi amastigote lysate for $16 \mathrm{~h}$ at $37{ }^{\circ} \mathrm{C}$ and $5 \% \mathrm{CO}_{2}$. Cells were assayed for IFNy production using the Canine IFN- $\gamma$ ELISpot kit (cat no. EL781, R\& D Systems, Inc, Minneapolis, MN, USA) following standard kit protocol. Enumeration of spot forming cells was completed by an ImmunoSpot analyzer (CTL, Cleveland, $\mathrm{OH}, \mathrm{USA})$. Mean numbers of spots from duplicate or triplicate well were obtained for media and T. cruzi lysate stimulation conditions. Responses were considered positive if a minimum of 20 spots $/ 10^{6}$ PBMC total were present and this number was at least twice the value of wells assayed with media alone [27].

\section{Intracellular cytokine staining}

For assaying IFN $\gamma$ production, $4 \times 10^{5} \mathrm{PBMCs}$ were stimulated for $5 \mathrm{~h}$ in the presence of $2 \mathrm{ng} / \mathrm{mL}$ PMA, $4 \mu \mathrm{g} / \mathrm{mL}$ $\mathrm{Ca}^{2+}$ ionomycin (Sigma-Aldrich), and brefeldin A (BD GolgiPlug; BD Biosciences, San Jose, CA, USA) adapted from described stimulation conditions [32] or overnight with $40 \mu \mathrm{g} / \mathrm{mL}$ T. cruzi lysate at $37{ }^{\circ} \mathrm{C}$. Brefeldin A was added $5 \mathrm{~h}$ prior to end of incubation, and the cells were stained with anti-CD8-Pacific Blue and anti-CD4-FITC (AbD Serotec, Raleigh, NC, USA) followed by intracellular staining with anti-bovine IFN- $\gamma$ AF647 (AbD Serotec) according to the BD Cytofix/Cytoperm kit (BD Biosciences). Samples were fixed in $2 \%$ formaldehyde prior to analysis by flow cytometry.

\section{CTL2.58 purification and PE-Cy7 labeling}

Culture supernatants containing clone CTL2.58 IgG were a kind gift of Dr Mary Tompkins, North Carolina State University, Raleigh, NC. Immunoglobulins were purified according to instructions of the Pierce Thiophilic Adsorption Kit (cat no 44916, Thermo Scientific, Rockford, IL, USA). Elutions containing targeted heavy and light chain were confirmed by SDS-PAGE and conjugated to PE-Cy7 using Lightning-Link PE-Cy7 antibody labeling kit (cat no 762-0015, Novus Biologicals, Littleton, CO, USA) following manufacture instructions. ConA-stimulated canine PBMCs were used for positive reactivity for CTL2.58-Pe-Cy7 staining (Additional file 1).

\section{Cell surface phenotyping}

PBMCs (500 000) were incubated in complete RPMI 1640 supplemented with $10 \%$ heat-inactivated FCS for $1 \mathrm{~h}$ at $37{ }^{\circ} \mathrm{C}$, centrifuged, and resuspended in $100 \mu \mathrm{L}$ of CCL19hIg (ELC; [33]) culture supernatant for $45 \mathrm{~min}$ at $4{ }^{\circ} \mathrm{C}$. After incubation, cells were washed and resuspended for staining in PAB solution containing PBS with 1\% BSA and $0.05 \%$ sodium azide (both from Sigma-Aldrich). Antibodies used were anti-CD8 PacBlue, anti-CD4 AF647, anti-CD62L PE (AbD Serotec), CTL2.58-PeCy7, and antihuman IgG AF488 (Molecular Probes, Eugene, OR, USA). 7-amino-actinomycin D (7AAD, BD Pharmingen, BD Biosciences, San Jose, CA, USA) was included for live/ dead cell discrimination. Following incubation of PBMCs with antibody mixes for 45 min on ice, cells were washed twice, fixed in $2 \%$ formaldehyde, and analyzed by flow cytometry.

\section{Flow cytometry and statistical analysis}

Fixed PBMC samples were collected on a CyAn ADP using Summit, version 4.3 (Beckman Coulter, Fullerton, CA, USA). FlowJo flow cytometry analysis software, version 8 (Tree Star, Ashland, OR, USA) was used for analyses. Positive gates were determined by relevant fluorescence 
Table 1 Comparison of xenodiagnosis, initial conventional serology, multiplex serology, and IFN $\gamma$ ELISpot assays

\begin{tabular}{|c|c|c|c|c|}
\hline Dog ID\# & Xenodiagnosis & $\begin{array}{l}\text { Initial } \\
\text { serology }\end{array}$ & $\begin{array}{l}\text { Multiplex } \\
\text { serology }\end{array}$ & $\begin{array}{l}\text { IFNy ELISpot } \\
\text { SFU }\end{array}$ \\
\hline \multicolumn{5}{|c|}{ Non-responders } \\
\hline$\overline{160}$ & - & - & 0 & 0 \\
\hline$\overline{163}$ & - & - & 0 & 0 \\
\hline 280 & - & - & 0 & 0 \\
\hline 281 & - & - & 0 & 0 \\
\hline 283 & - & - & 0 & 3 \\
\hline 187 & n.d. & - & 0 & 0 \\
\hline 258 & n.d. & - & 0 & 0 \\
\hline 259 & n.d. & - & 0 & 0 \\
\hline$\overline{267}$ & n.d. & - & 0 & 0 \\
\hline 198 & n.d. & + & 0 & 0 \\
\hline 200 & n.d. & + & 0 & 0 \\
\hline 588 & n.d. & discordant & 1 & 0 \\
\hline 260 & n.d. & n.d. & 0 & 0 \\
\hline $\bar{B}$ & n.d. & n.d. & 0 & 0 \\
\hline$\overline{\mathrm{D}}$ & n.d. & n.d. & 0 & 0 \\
\hline $\bar{F}$ & n.d. & n.d. & 0 & 0 \\
\hline I & n.d. & n.d. & 0 & n.d. \\
\hline J & n.d. & n.d. & 0 & 0 \\
\hline$\overline{\mathrm{K}}$ & n.d. & n.d. & 0 & 3 \\
\hline $\mathrm{L}$ & n.d. & n.d. & 0 & 0 \\
\hline $\bar{M}$ & n.d. & n.d. & 0 & 0 \\
\hline
\end{tabular}

\begin{tabular}{|c|c|c|c|c|}
\hline & & & $0 / 21$ & $0 / 20$ \\
\hline \multicolumn{5}{|c|}{ Responders } \\
\hline 152 & - & + & 6 & 400 \\
\hline$\overline{71}$ & + & + & 5 & 55 \\
\hline 154 & + & + & 3 & 108 \\
\hline 157 & + & + & 5 & $13(-)$ \\
\hline 159 & + & + & 3 & 290 \\
\hline 266 & + & n.d. & 3 & 55 \\
\hline 272 & + & + & 2 & 50 \\
\hline 274 & + & + & 2 & 68 \\
\hline 276 & + & + & 4 & 363 \\
\hline 284 & + & + & 3 & 955 \\
\hline$\overline{43}$ & n.d. & + & 4 & 233 \\
\hline$\overline{67}$ & n.d. & + & 1 & 80 \\
\hline 69 & n.d. & + & 5 & 550 \\
\hline 193 & n.d. & + & 4 & 130 \\
\hline 197 & n.d. & + & 2 & 63 \\
\hline 434 & n.d. & + & 5 & 58 \\
\hline 572 & n.d. & + & 4 & n.d. \\
\hline$\overline{573}$ & n.d. & + & 3 & 398 \\
\hline 589 & n.d. & + & 4 & 33 \\
\hline $\bar{P}$ & n.d. & n.d. & 3 & 823 \\
\hline$\overline{\mathrm{O}}$ & n.d. & n.d. & 5 & 520 \\
\hline & & & $20 / 21$ & $19 / 20$ \\
\hline
\end{tabular}

\begin{tabular}{lllll}
\hline & & & $\mathbf{2 0 / 2 1}$ & $\mathbf{1 9 / 2 0}$ \\
\hline Controls (US) & & & & \\
\hline 1 & n.d. & n.d. & 0 & 0 \\
\hline 2 & n.d. & n.d. & 0 & 3 \\
\hline 4 & n.d. & n.d. & 0 & 0 \\
\hline 5 & n.d. & n.d. & 0 & n.d. \\
\hline 6 & n.d. & n.d. & 0 & n.d. \\
\hline 7 & n.d. & n.d. & 0 & n.d. \\
\hline 8 & n.d. & n.d. & 0 & n.d. \\
\hline & n.d. & n.d. & 0 & n.d. \\
\hline
\end{tabular}

Forty-two samples from dogs living in a T. cruzi-endemic region are grouped as nonresponders and responders based on reactivity to $T$. cruzi lysate in serological and effector function assays. Test reactivity is annotated as positive (+), negative (-), discordant (disc), or not determined (n.d.). Controls are canine samples from dogs living in the United States. Bold data are results presented as \# positive individuals/\# total individuals of the groups. minus one controls. Statistical analyses were performed using Prism v4.0c (GraphPad Software, La Jolla, CA, USA).

\section{Results}

Our first aim was to test an improved serodiagnostic assay for the ability to detect T. cruzi infection in canines. Sera and plasma samples were obtained from eight healthy dogs from the United States (US) and forty-two dogs living in a $T$. cruzi-endemic region of northern Argentina. Twenty Argentinean dogs were known to be seropositive, nine seronegative, and one discordant by conventional serology two years prior to this study. Ten dogs were new additions to domiciles and had not been previously tested. We employed a multiplex bead array format previously utilized for identifying and discriminating humans reactive to recombinant $T$. cruzi proteins, in which proteins were selected for their predicted expression during mammalian infection stages and high abundance in the trypomastigote and amastigote T. cruzi proteome [20]. Addressable beads were bound to eleven recombinant $T$. cruzi proteins, incubated with sera or plasma, followed with a secondary fluorophore conjugated anti-canine specific IgG, and quantified on a BioPlex Suspension Array System (BioRad) for mean fluorescence intensity (MFI). We first tested a subset of dogs and found that as expected, animals positive by conventional serology had considerably higher MFI values than United States control dogs or seronegative Argentinean dogs (Figure 1). All proteins in the multiplex assay showed reactivity with serum from at least one dog with a subset of six recombinant proteins (60S acidic ribosomal subunit protein, microtubule-associated protein homolog, glycosomal phosphoenolpyruvate carboxylase, flagellar calcium binding protein, major paraflagellar rod protein, and a hypothetical protein) identifying all initial conventional serology positive canines. All conventional serology positive dogs showed reactivity above a MFI of 10000 to at least one protein or greater than $6500 \mathrm{MFI}$ for at least four proteins in the multiplex array. One discordant dog, dog 588, had no significant responses to the subset of six recombinant proteins identifying all conventional serology positive canines. However dog 588 did have greater than 10000 MFI to calmodulin proteincoated beads, but this reactivity was not observed in any other dog. These results validate a multiplex serological assay platform for identifying circulating anti-T. cruzi antibodies in the dog using mammalian-stage derived T. cruzi-recombinant proteins.

We next tested all Argentinean canine plasma samples creating a metric of reactivity by calculating the standard deviation of each individual plasma sample for each individual protein over reactivity to all conventional serology negative animals. Using a minimum reactivity to two proteins with four standard deviations above that of the seronegative individuals, ninety-four percent (17/18) of 
the dogs positive by multiplex serology were initially positive with conventional serology (Table 1). Two conventional serology positive dogs (dogs 198 and 200) had no significant responses to any recombinant proteins in the multiplex assay. All nine initial seronegative dogs were also negative in the multiplex bead serological assay. Analysis of eleven dogs without previous conventional serology revealed two additional seropositive animals, dog $\mathrm{O}$ and $\mathrm{P}$.

Measurement of T. cruzi-specific $\mathrm{T}$ cells has proven useful for confirming and monitoring infection status in humans $(23,27)$. PBMCs from dogs were evaluated for IFN $\gamma$ production by ELISpot following stimulation with T. cruzi lysate or PMA/ionomycin. Using 20 spot forming units (SFU) $/ 10^{6}$ PBMCs as a cutoff for positive ELISpot responses, 95\% (19/20) of dogs seropositive by multiplex were also positive in the ELISpot assay while 96\% $(24 / 25)$ of multiplex seronegative dogs from Argentina or the United States were ELISpot negative (Figure 2 and Table 1). Significantly higher frequencies of IFNYproducing $\mathrm{T}$ cells in seropositive animals following PBMC incubation with PMA/ionomycin suggested these dogs had a higher overall active $\mathrm{T}$ cell compartment as compared to seronegative dogs (Figure 2C). Little to no spontaneous IFNY production confirms the specificity of the ELISpot assay to identify $T$. cruzi-specific T cells in the dog.

To phenotype the IFNY producing cells, PBMCs from a subset of ELISpot positive and negative dogs were incubated with $T$. cruzi lysate and assessed for intracellular IFN $\gamma$ production and co-stained for expression of $\mathrm{CD}^{+}$ or $\mathrm{CD}^{+}$(Figure 3A). Of the four ELISpot positive dogs, three possessed $\mathrm{CD}^{+}$and $\mathrm{CD}^{+}{ }^{+} \mathrm{T}$ cells producing IFNY in response to lysate stimulation, while one dog, $\operatorname{dog} 67$, had only $\mathrm{CD}^{+} \mathrm{T}$ cells producing IFN $\gamma$ in response to lysate stimulation (Figure 3B-C). Taken together, these data demonstrate that a high percentage of $T$. cruzi-infected dogs have measurable $\mathrm{CD}^{+}$and $\mathrm{CD}^{+}{ }^{+} \mathrm{T}$ cells responsive to T. cruzi lysate.

As $T$ cell surface markers of activation and effector $\mathrm{T}$ cell memory correlate with $T$. cruzi infection and disease severity in humans [26,34], we next evaluated the impact of $T$. cruzi infection on surface antigen expression on canine $\mathrm{T}$ cells. Recent validation of $\mathrm{T}$ cell surface markers identifying canine $\mathrm{T}$ cells with activated $\left(\mathrm{CTL} 2.58^{+}\right)$and naïve or central memory $\left(\mathrm{CCR} 7^{+} \mathrm{CD} 62 \mathrm{~L}^{\text {hi }}\right)$ phenotypes has provided cell surface markers for delineating canine $\mathrm{T}$ cell phenotypes (Additional file 1 and Hartley and Tarleton, unpublished). Examining the $\mathrm{CD}^{+}$(Figure 4A) and $\mathrm{CD}_{4}^{+}$(Figure 4B) T cell compartments, both T cell subsets expressed measurable levels of CCR7, CD62L, and CTL2.58. The expression and co-expression of naïve or central memory markers CCR7 and CD62L in T cells from healthy US control dogs were consistently higher or significantly higher as compared to the Argentinean dogs for both $\mathrm{CD}^{+}$and $\mathrm{CD} 4^{+} \mathrm{T}$ cell subsets (Figure 4C-E, G-I). These differentiating results most likely reflect the inherent environmental variation of dogs living in the United States receiving preventative care versus dogs living in a T. cruzi-endemic region with limited accessible veterinary care, and thus a higher likelihood of harboring a range of infectious agents. The antibody CTL2.58, a reagent likely recognizing recently activated $\mathrm{T}$ cells and which showed strong reactivity with both Con A stimulated canine $\mathrm{T}$ cells (Additional file 1), did not appear differentially expressed across any of the dog groups (Figure $4 \mathrm{~F}$ and J), but high CTL2.58 expression by $\mathrm{CD}^{+} \mathrm{T}$ cells from a seropositive dog (Figure 4A) suggested recent $\mathrm{T}$ cell activation had occurred in this dog. Overall, these $\mathrm{T}$ cell

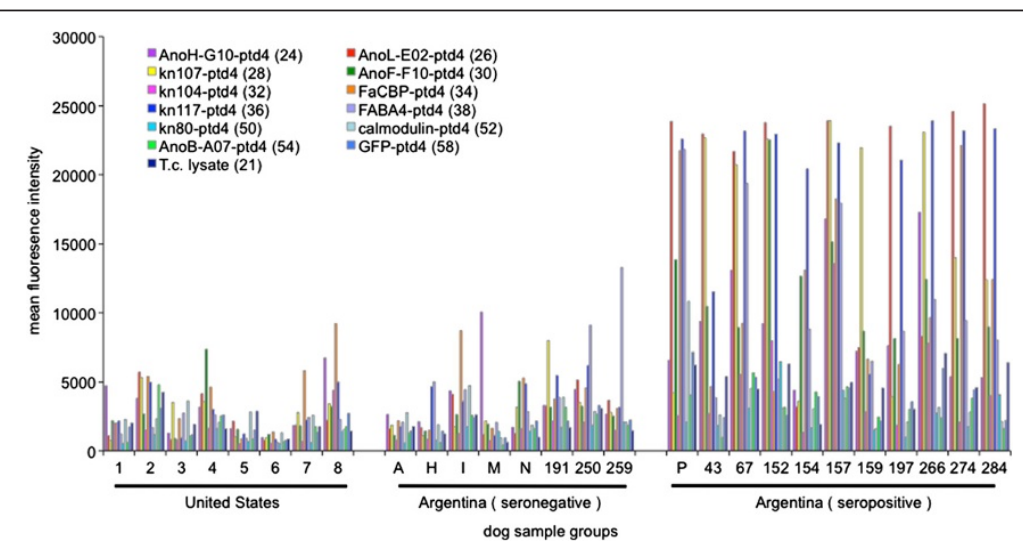

Figure 1 Canine plasma samples tested with a multiplex bead array correlate with initial conventional serology results. Reactivity to 11 T. cruzi recombinant proteins in sera or plasma from conventional serology positive (seropositive) and negative (seronegative) dogs living in a T. cruzi-endemic region of Argentina and canine sera obtained from dogs in the United States. Vertical bars represent mean fluorescence intensity (MFI) to the recombinant protein on a scale from 0 to 30000 arbitrary light units. Recombinant GFP and T. cruzi lysate-coated beads served as negative and positive controls, respectively. 

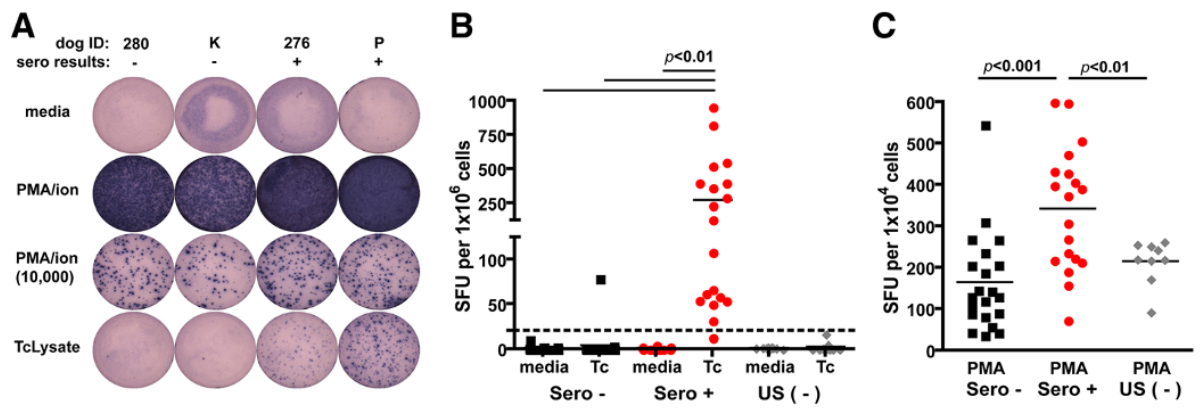

Figure 2 Seropositive dogs have significantly higher frequencies of $T$. cruzi-specific PBMCs and reactive T cell compartment. A, Interferon (IFN)- $\gamma$ enzyme-linked immmunosorbent spot (ELISpot) well images of $4 \times 10^{5}$ PBMCs cultured with media, PMA/ionomycin (PMA/ion), or T. cruzi lysate (TCLysate/Tc) and $1 \times 10^{4}$ PBMCs stimulated with PMA/ionomycin (PMA/ion (10 000)). Individual dog identification (ID) and results of multiplex serology are denoted above wells. B-C, Numbers of IFNy-producing PBMCs in the ELISpot assay responding to T. cruzi parasite lysate (B) or PMA (C) adjusted to $1 \times 10^{6}$ or per $1 \times 10^{4}$ PBMCs, respectively. Each square and dot represents an individual dog, while each diamond represents one of three US dog controls to ensure plate reproducibility. Dogs are grouped by multiplex serology negative (Sero -) or serology positive (Sero +) from Argentina or seronegative dogs from United States. Statistical significance was determined by one-way ANOVA using Prism v4.0c (GraphPad). Horizontal line, threshold for positive/negative response.

surface markers correlate a positive T. cruzi serological status with a robust activated T. cruzi-specific $T$ cell response.

\section{Discussion}

T. cruzi-infected dogs are a major factor in transmission of T. cruzi to humans [3] and are present in both rural and urban settings [35]. Thus, identification of infected dogs is critical for design and appropriate targeting of T. cruzi transmission control and intervention strategies. Towards this goal, we first tested the ability of an improved serological assay utilizing $T$. cruzi proteins expressed in mammalian-stage parasites [20] to detect $T$. cruzi infection in dogs. Though the protein panel selected for this multiplex assay was originally defined for discriminating human sera, initial tests with a subset of dog sera or plasma revealed high reactivity as well (Figure 1). In particular, a six-protein subset was highly discriminatory for serological status, with a minimum two-protein reactivity of four standard deviations above seronegative animals identifying 94\% (17/18) of multiplex serology positive dogs that were positive by conventional serology (Table 1). Selection and screening of additional proteins with canine plasma samples, including a broader set of discordant dogs, would likely improve upon this multiplex bead array assay. A single test format that conclusively determines infection status, as opposed to the current method of using multiple platforms and the resulting "discordant" samples, would represent an improvement in diagnostics for dogs.

To our knowledge, this was the first study to evaluate and correlate the T. cruzi-specific antibody response with $\mathrm{T}$ cell phenotype and effector cytokine production in dogs. In humans, decreases in antibody responses and in the frequency of $T$. cruzi-induced IFN $\gamma$-production by $\mathrm{T}$ cells and following benznidazole treatment have provided methods to evaluate infection and treatment efficacy in people. In the present study, our aim was to determine if antibody responses in dogs naturally infected with $T$. cruzi correlated with $T$. cruzi-specific $T$ cell responses, in efforts for ultimately identifying methods to track canine T. cruzi infection. In contrast with human IFN $\gamma$ ELISpot assays, where IFNY-producing PBMCs were detected in $58 \%$ of seropositive and $35 \%$ of conventional seronegative individuals living in areas of active transmission [36], $95 \%$ of seropositive dogs and $4 \%$ of seronegative dogs were positive in the canine IFNy-ELISpot assay. These data suggest dogs not only develop robust $\mathrm{T}$ cells response during $T$. cruzi infection but the $T$. cruzi-specific immune responses are much more apparent than those present in humans. Relatively shorter terms of T. cruzi infection in dogs, i.e. months to years versus decades in humans, and the resultant decreased potential for $\mathrm{T}$ cell exhaustion, as observed in human patients [34], may explain the disparity in seroreactivity and ELISpot results observed between humans and dogs. Intracellular cytokine staining allowed us to identify both $\mathrm{CD}^{+}$and $\mathrm{CD} 8^{+} \mathrm{T}$ cells as responsible for IFN $\gamma$ production in selected dogs (Figure 3) at various, but low frequencies. Similar low frequency of IFN $\gamma$ response to T. cruzi lysate has been documented in human Chagasic patients [27]. The robust frequency of IFN $\gamma$-producing $\mathrm{T}$ cells observed in seropositive dogs in the ELISpot assay provides a diagnostic method to detect, monitor, and track canine T. cruzi infection. We would predict that, as in humans, dogs treated with curative anti-T. cruzi drugs would exhibit predictable changes in the frequencies of these T. cruzi-specific $\mathrm{T}$ cell responses [23].

Additionally, the correlation of various $\mathrm{T}$ cell surface markers with drug-induced cure has defined $\mathrm{T}$ cell 


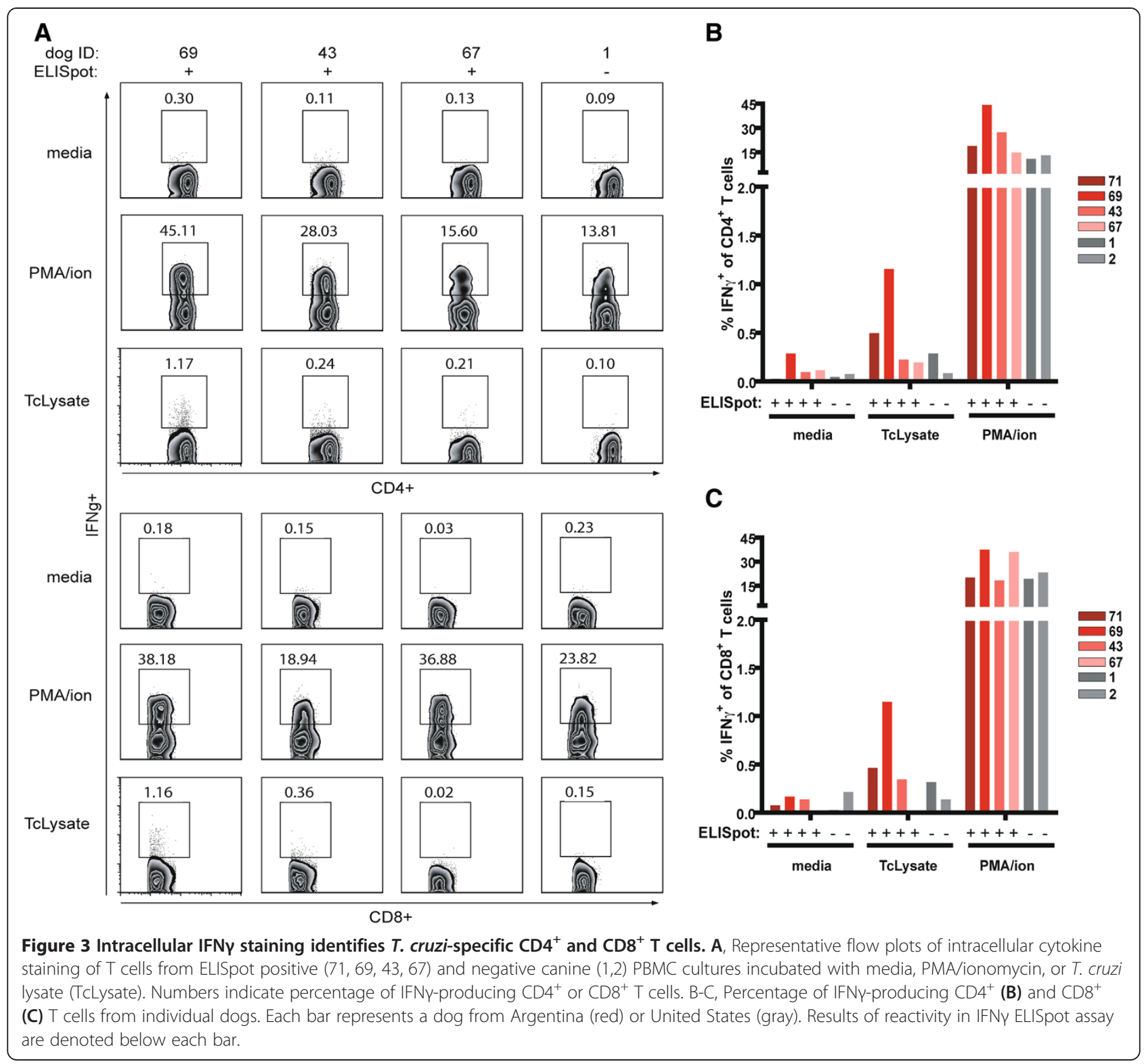

biomarkers for assessing antigen encounter and parasite burden during murine T. cruzi infection [30]. Similar work in humans have correlated $\mathrm{T}$ cell surface marker changes with post benznidazole treatment periods [23], although the inability to measure these markers on bona fide T. cruzi-specific T cells [27] provides a less dependable marker of treatment efficacy than is possible in the mouse, where these $\mathrm{T}$ cells area easily monitored using MHC tetramers. Utilizing $\mathrm{T}$ cell-specific surface markers validated for the dog, phenotyping of canine PBMCs provided a method to assess hypothesized differences in global $\mathrm{T}$ cell surface marker expression between seropositive and seronegative animals. Though not statistically significant, higher expression of CCR7 and CD62L in seronegative versus seropositive $\operatorname{dog} \mathrm{T}$ cells are consistent with these cell surface markers identifying naïve or central memory $\mathrm{T}$ cells. Seropositive dogs, on the other hand, possessed $\mathrm{CD}^{+}$and $\mathrm{CD}^{+}{ }^{+} \mathrm{T}$ cells expressing decreased levels of CCR7 and CD62L. Further monitoring of these T cell surface markers during the course of canine T. cruzi infection and particularly on IFN $\gamma$-producing cells, would greatly enhance our understanding development, maintenance, and persistence of the canine $\mathrm{T}$ cell immune responses for evaluating various intervention strategies focused on the dog.

In addition to being important players in the transmission of T. cruzi to humans [3,4,6,7], as natural hosts that suffer clinical manifestations of Chagasic disease $[37,38]$, and as models for testing of anti-trypanosomal drugs [39], canines are strong translational models for 


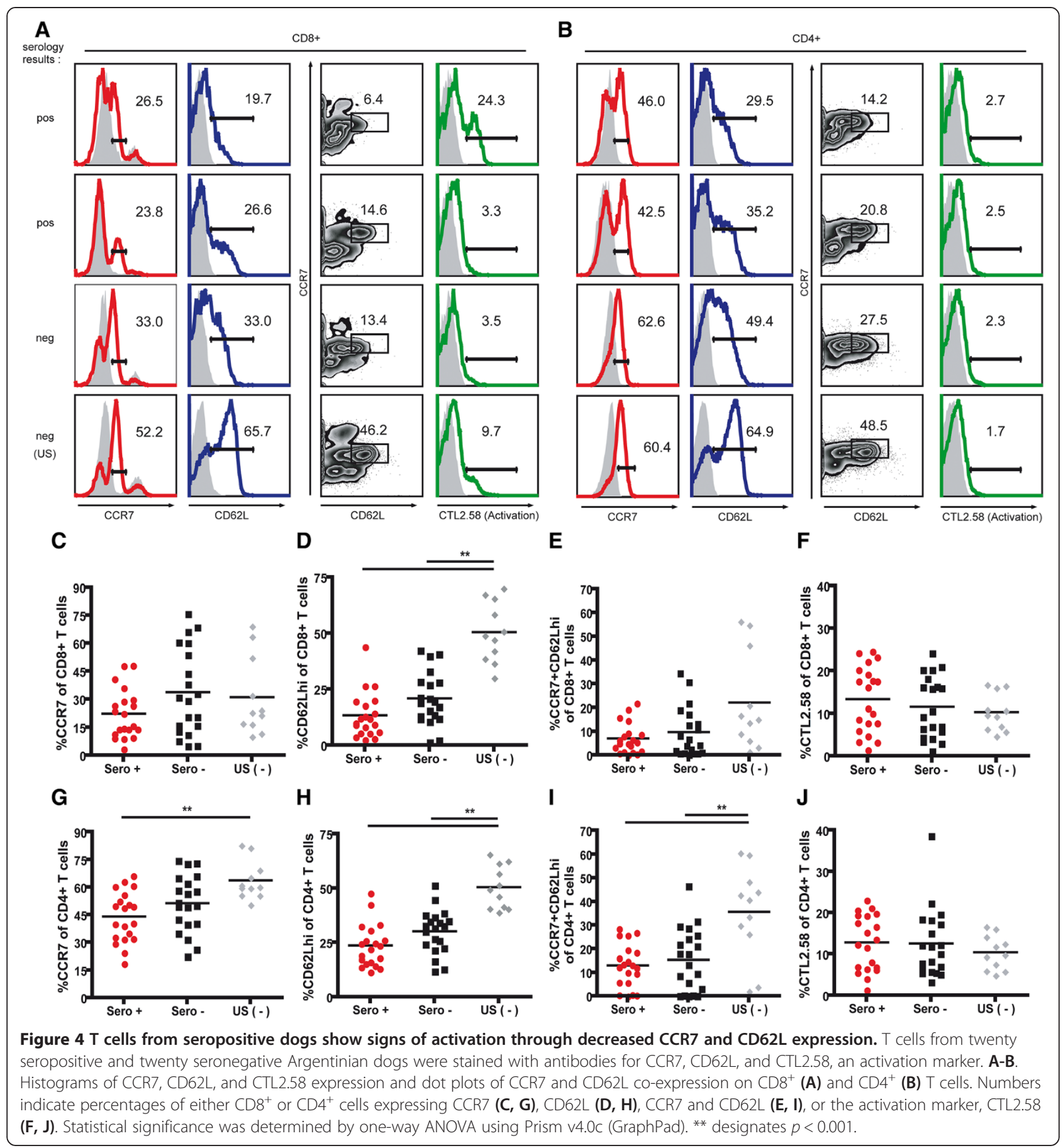

studying human T. cruzi infection. Understanding and characterizing the canine $T$. cruzi-specific immune response is imperative for identifying infected canines in regions of active transmission, evaluating the efficacy of targeted canine intervention strategies, including potential vaccine strategies, and overall improving our knowledge of antibody and $\mathrm{T}$ cells responses during canine disease. The full impact and application of serology and $T$ cell responses for tracking and monitoring canine T. cruzi infection and evaluating T. cruzi transmission dynamics have yet to be determined.

\section{Additional file}

Additional file 1: Induction of CTL2.58 expression on canine PBMCs following stimulation with Con A. Canine PBMCs incubated two days with media or ConA, harvested, and stained to identify $C D 4^{+}$and $C D 8^{+}$ $T$ cells and the expression of CTL2.58 (conjugated to PeCy7). Numbers 
indicate the percentage of $\mathrm{CD}^{+}$and $\mathrm{CD} 8^{+} \mathrm{T}$ cells among PBMCs (left column) and the percentage of these subpopulations positive for the activation molecule recognized by CTL2.58 antibody with or without Con A stimulation (center and right columns).

\section{Competing interests}

The authors declare they have no competing interests.

\section{Authors' contributions}

ANH and RLT conceived and designed the experiments. ANH, GC, MMO, and SG performed the experiments. ANH, GC, MMO, and RLT analyzed the data. $\mathrm{ANH}, \mathrm{GC}, \mathrm{MMO}$, and RLT contributed reagents/materials/analysis tools. ANH and RLT wrote the manuscript. All authors read and approved the final manuscript.

\section{Acknowledgements}

We greatly acknowledge Dr. Ricardo Gürtler of the University of Buenos Aires, Argentina for acquisition of canine samples from Pampa del Indio, Chaco Province, Argentina. We thank Dr. Susana A. Laucella, Dr. María Cecilia Albareda, and Damián Pérez Mazliah of the Instituto Nacional de Parasitología "Dr. M. Fatala Chaben" of Buenos Aires Argentina for technical assistance with Argentina PBMC purification and ELISpot advisement, Lisa Reno of the University of Georgia College of Veterinary Medicine, Julie Nelson of the Center for Tropical and Emerging Global Diseases Flow Cytometry Facility at the University of Georgia, Donna Huber for secretarial assistance and members of the Tarleton Research Group for helpful discussion. ANH was supported in part by an Ellison Medical Foundation/ Center for Tropical and Emerging Global Diseases (EMF/CTEGD) Training in Parasitologic Studies Program (TIPS) fellowship and an NIH training grant T32 Al-060546 to the CTEGD. This work was supported by NIH Grant POI Al044979 and R01 Al089952 awarded to RLT.

\section{Author details}

${ }^{1}$ Center for Tropical and Emerging Global Diseases, University of Georgia, Athens, GA 30602, USA. ${ }^{2}$ Department of Infectious Diseases, University of Georgia, Athens, GA 30602, USA. ${ }^{3}$ Departamento de Ecología, Laboratori de Eco-Epidemiología, Genética y Evolución, Facultad de Ciencias Exactas y Naturales, Universidad de Buenos Aires, Ciudad Autónoma de Buenos Aires, Argentina. ${ }^{4}$ Department of Cellular Biology, University of Georgia, Athens, GA 30602, USA.

Received: 3 June 2013 Accepted: 7 January 2014

Published: 23 January 2014

\section{References}

1. Chagas disease (American trypanosomiasis). [http://www.who.int/ mediacentre/factsheets/fs340/en/index.html]

2. Stuart K, Brun R, Croft S, Fairlamb A, Gurtler RE, McKerrow J, Reed S, Tarleton R: Kinetoplastids: related protozoan pathogens, different diseases. J Clin Invest 2008, 118:1301-1310.

3. Gürtler RE, Cecere MC, Lauricella MA, Cardinal MV, Kitron U, Cohen JE: Domestic dogs and cats as sources of Trypanosoma cruzi infection in rural northwestern Argentina. Parasitology 2007, 134:69-82.

4. Cohen JE, Gürtler RE: Modeling household transmission of American trypanosomiasis. Science 2001, 293:694-698.

5. Gürtler RE, Ceballos LA, Ordonez-Krasnowski P, Lanati LA, Stariolo R, Kitron $\mathrm{U}$ : Strong host-feeding preferences of the vector Triatoma infestans modified by vector density: implications for the epidemiology of Chagas disease. PloS Negl Trop Dis 2009, 3:e447.

6. Gürtler RE, Cecere MC, Castanera MB, Canale D, Lauricella MA, Chuit R, Cohen JE, Segura EL: Probability of infection with Trypanosoma cruzi of the vector Triatoma infestans fed on infected humans and dogs in northwest Argentina. Am J Trop Med Hyg 1996, 55:24-31.

7. Lauricella MA, Sinagra AJ, Paulone I, Riarte AR, Segura EL: Natural Trypanosoma cruzi infection in dogs of endemic areas of the Argentine Republic. Rev Inst Med Trop Sao Paulo 1989, 31:63-70.

8. Reithinger R, Ceballos L, Stariolo R, Davies CR, Gürtler RE: Extinction of experimental Triatoma infestans populations following continuous exposure to dogs wearing deltamethrin-treated collars. Am J Trop Med Hyg 2006, 74:766-771.
9. Basombrio MA, Segura MA, Mora MC, Gomez L: Field trial of vaccination against American trypanosomiasis (Chagas' disease) in dogs. Am J Trop Med Hyg 1993, 49:143-151.

10. Aparicio-Burgos JE, Ochoa-Garcia L, Zepeda-Escobar JA, Gupta S, Dhiman M, Martinez JS, de Oca-Jimenez RM, Arreola MV, Barbabosa-Pliego A, Vazquez-Chagoyan JC, Garg NJ: Testing the efficacy of a multi-component DNA-prime/DNA-boost vaccine against Trypanosoma cruzi infection in dogs. PloS Negl Trop Dis 2011, 5:e1050.

11. Basso B, Castro I, Introini V, Gil P, Truyens C, Moretti E: Vaccination with Trypanosoma rangeli reduces the infectiousness of dogs experimentally infected with Trypanosoma cruzi. Vaccine 2007, 25:3855-3858.

12. Salomone $O A$, Basquiera $A L$, Sembaj A, Aguerri $A M$, Reyes $M E$, Omelianuk M, Fernandez RA, Enders J, Palma A, Barral JM, Madoery RJ: Trypanosoma cruzi in persons without serologic evidence of disease, Argentina. Emerg Infect Dis 2003, 9:1558-1562.

13. Marcon GE, Andrade PD, de Albuquerque DM, Wanderley Jda S, de Almeida EA, Guariento ME, Costa SC: Use of a nested polymerase chain reaction (N-PCR) to detect Trypanosoma cruzi in blood samples from chronic chagasic patients and patients with doubtful serologies. Diagn Microbiol Infect Dis 2002, 43:39-43.

14. Zarate-Blades CR, Blades N, Nascimento MS, da Silveira JF, Umezawa ES: Diagnostic performance of tests based on Trypanosoma cruzi excreted-secreted antigens in an endemic area for Chagas' disease in Bolivia. Diagn Microbiol Infect Dis 2007, 57:229-232.

15. Lauricella MA, Castanera MB, Gürtler RE, Segura EL: Immunodiagnosis of Trypanosoma cruzi (Chagas' disease) infection in naturally infected dogs. Mem Inst Oswaldo Cruz 1998, 93:501-507.

16. Montenegro VM, Jimenez M, Dias JCP, Zeledon R: Chagas disease in dogs from endemic areas of Costa Rica. Mem Inst Oswaldo Cruz 2002, 97:491-494.

17. Lauricella MA, Wisnivesky-Colli C, Gürtler R, Petersen R, Bujas M, Segura EL: Standardization of serological tests for detecting anti-Trypanosoma-cruzi antibodies in dogs. Mem Inst Oswaldo Cruz 1993, 88:413-417.

18. Minning TA, Weatherly DB, Atwood J 3rd, Orlando R, Tarleton RL: The steady-state transcriptome of the four major life-cycle stages of Trypanosoma cruzi. BMC Genomics 2009, 10:370.

19. Atwood JA 3rd, Weatherly DB, Minning TA, Bundy B, Cavola C, Opperdoes FR, Orlando R, Tarleton RL: The Trypanosoma cruzi proteome. Science 2005, 309:473-476.

20. Cooley G, Etheridge RD, Boehlke C, Bundy B, Weatherly DB, Minning T, Haney M, Postan M, Laucella S, Tarleton RL: High throughput selection of effective serodiagnostics for Trypanosoma cruzi infection. PLoS Negl Trop Dis 2008, 2:e316

21. Tarleton RL: Depletion of CD8+ T cells increases susceptibility and reverses vaccine-induced immunity in mice infected with Trypanosoma cruzi. J Immunol 1990, 144:717-724.

22. Tarleton RL, Koller BH, Latour A, Postan M: Susceptibility of beta 2-microglobulin-deficient mice to Trypanosoma cruzi infection. Nature 1992, 356:338-340.

23. Laucella SA, Mazliah DP, Bertocchi G, Alvarez MG, Cooley G, Viotti R, Albareda MC, Lococo B, Postan M, Armenti A, Tarleton RL: Changes in Trypanosoma cruzi-specific immune responses after treatment: surrogate markers of treatment efficacy. Clin Infect Dis 2009, 49:1675-1684.

24. Tarleton RL, Grusby MJ, Postan M, Glimcher LH: Trypanosoma cruzi infection in MHC-deficient mice: further evidence for the role of both class I- and class II-restricted T cells in immune resistance and disease. Int Immunol 1996, 8:13-22.

25. Tarleton RL, Sun J, Zhang L, Postan M: Depletion of T-cell subpopulations results in exacerbation of myocarditis and parasitism in experimental Chagas' disease. Infect Immun 1994, 62:1820-1829.

26. Albareda MC, Laucella SA, Alvarez MG, Armenti AH, Bertochi G, Tarleton RL, Postan M: Trypanosoma cruzi modulates the profile of memory CD8+ T cells in chronic Chagas' disease patients. Int Immunol 2006, 18:465-471.

27. Laucella SA, Postan M, Martin D, Hubby Fralish B, Albareda MC, Alvarez MG, Lococo B, Barbieri G, Viotti RJ, Tarleton RL: Frequency of interferongamma -producing $T$ cells specific for Trypanosoma cruzi inversely correlates with disease severity in chronic human Chagas disease. J Infect Dis 2004, 189:909-918.

28. Michailowsky V, Silva NM, Rocha CD, Vieira LQ, Lannes-Vieira J, Gazzinelli RT: Pivotal role of interleukin-12 and interferon-gamma axis in controlling tissue parasitism and inflammation in the heart and central nervous system during Trypanosoma cruzi infection. Am J Pathol 2001, 159:1723-1733. 
29. Martin DL, Weatherly DB, Laucella SA, Cabinian MA, Crim MT, Sullivan S, Heiges M, Craven SH, Rosenberg CS, Collins MH, Sette A, Postan M, Tarleton RL: CD8+ T-Cell responses to Trypanosoma cruzi are highly focused on strain-variant trans-sialidase epitopes. PLoS Pathog 2006, 2:e77.

30. Bustamante JM, Bixby LM, Tarleton RL: Drug-induced cure drives conversion to a stable and protective CD8+ T central memory response in chronic Chagas disease. Nat Med 2008, 14:542-550.

31. Enriquez GF, Cardinal MV, Orozco MM, Schijman AG, Gürtler RE: Detection of Trypanosoma cruzi infection in naturally infected dogs and cats using serological, parasitological and molecular methods. Acta Trop 2013, 126:211-217.

32. Pedersen $L G$, Castelruiz $Y$, Jacobsen $S$, Aasted B: Identification of monoclonal antibodies that cross-react with cytokines from different animal species. Vet Immunol Immunopathol 2002, 88:111-122.

33. Hargreaves DC, Hyman PL, Lu TT, Ngo VN, Bidgol A, Suzuki G, Zou YR, Littman DR, Cyster JG: A coordinated change in chemokine responsiveness guides plasma cell movements. J Exp Med 2001, 194:45-56.

34. Albareda MC, Olivera GC, Laucella SA, Alvarez MG, Fernandez ER, Lococo B, Viotti R, Tarleton RL, Postan M: Chronic human infection with Trypanosoma cruzi drives CD4+ T cells to immune senescence. $\mathrm{J}$ Immunol 2009, 183:4103-4108.

35. Jimenez-Coello M, Poot-Cob M, Ortega-Pacheco A, Guzman-Marin E, Ramos-Ligonio A, Sauri-Arceo CH, Acosta-Viana KY: American trypanosomiasis in dogs from an urban and rural area of Yucatan, Mexico. Vector Borne Zoonotic Dis 2008, 8:755-762

36. Olivera GC, Albareda MC, Alvarez MG, De Rissio AM, Fichera LE, Cooley G, Yachelini P, Hrellac HA, Riboldi H, Laucella SA, Tarleton RL, Postan M: Trypanosoma cruzi-specific immune responses in subjects from endemic areas of Chagas disease of Argentina. Microbes Infect 2010, 12:359-363.

37. Barr SC: Canine Chagas' disease (American trypanosomiasis) in North America. Vet Clin North Am Small Anim Pract 2009, 39:1055-1064.

38. Guedes PMM, Veloso VM, Afonso LCC, Caliari MV, Carneiro CM, Diniz LF, Marques-Da-Silva EA, Caldas IS, Matta MAD, Souza SM, Lana M, Chiari E, Galvão $L M$, Bahia MT: Development of chronic cardiomyopathy in canine Chagas disease correlates with high IFN-gamma, TNF-alpha, and low IL-10 production during the acute infection phase. Vet Immunol Immunopathol 2009, 130:43-52.

39. Guedes PMD, Veloso VM, Tafuri WL, Galvao LMD, Carneiro CM, de Lana M, Chiari E, Soares KA, Bahia MT: The dog as model for chemotherapy of the Chagas' disease. Acta Trop 2002, 84:9-17.

doi:10.1186/1297-9716-45-6

Cite this article as: Hartley et al:: Frequency of IFNy-producing T cells correlates with seroreactivity and activated T cells during canine Trypanosoma cruzi infection. Veterinary Research 2014 45:6.

\section{Submit your next manuscript to BioMed Central and take full advantage of:}

- Convenient online submission

- Thorough peer review

- No space constraints or color figure charges

- Immediate publication on acceptance

- Inclusion in PubMed, CAS, Scopus and Google Scholar

- Research which is freely available for redistribution

Submit your manuscript at www.biomedcentral.com/submit
Biomed Central 